\title{
Improving Mechanical Property and Microstucture Evolution of 7075 Aluminum Panel Formed by Unequal Alternate Double-sided Laser Shock Forming
}

\section{Yuqi Yang}

Shenyang Institute of Automation Chinese Academy of Sciences

Hongchao Qiao ( $\square$ hcqiao@sia.cn )

Shenyang Institute of Automation Chinese Academy of Sciences

Ying Lu

Shenyang Institute of Automation Chinese Academy of Sciences Jibin Zhao

Shenyang Institute of Automation Chinese Academy of Sciences boyu sun

Shenyang Institute of Automation Chinese Academy of Sciences jiaqi he

Shenyang Institute of Automation Chinese Academy of Sciences

\section{Research Article}

Keywords: laser shock forming, laser energy, thin panel thickness, harden layer, grain refinement

Posted Date: November 2nd, 2021

DOI: https://doi.org/10.21203/rs.3.rs-1026271/v1

License: (c) (i) This work is licensed under a Creative Commons Attribution 4.0 International License.

Read Full License 


\title{
Improving mechanical property and microstucture evolution of 7075 aluminum panel formed by unequal alternate double-sided laser shock forming
}

\author{
Yuqi Yang ${ }^{1,2,3}$, Hongchao Qiao ${ }^{1,2^{*}}$, Ying $\mathrm{Lu}^{1,2}$, Jibin Zhao ${ }^{1,2^{*}}$, Boyu Sun ${ }^{1,2}$, Jiaqi He $\mathrm{He}^{1,2,4}$ \\ 1. State Key Laboratory of Robotics, Shenyang Institute of Automation, Chinese Academy of Sciences, Shenyang \\ 110016, China; \\ 2. Institute for Robotics and Intelligent Manufacturing, Chinese Academy of Sciences, Shenyang 110169, China; \\ 3. University of Chinese Academy of Sciences, Beijing 100049, China; \\ 4. College of Material Science and Engineering, Shenyang University of Technology, Shenyang 110870, China. \\ *Corresponding author email: hcqiao@sia.cn (Hongchao Qiao); jbzhao@sia.cn (Jibin Zhao)
}

\begin{abstract}
:
With thrust weight ratio increasing, integral panel is an important component to reduce the aircraft weight, and it is a great challenges to ensure the forming accuracy and mechanical property in the lager-scale panel. Laser shock forming has a great development prospect in achieving integral panel forming and improving its mechanical properties. This work investigated unequal alternate double-sided laser shock forming, which can make 7075 aluminum panel form and induce harden layer in both panel sides. The improvement in mechanical properties and microstucture evolution of 7074 aluminum panel were analyzed after unequal alternate double-sided laser shock forming. The residual stress and microhardness in surface and subsurface were verified to be enhanced by the laser shock wave. The results of XRD and EBSD provided an evidence of grain refinement. The strengthening mechanism of unequal alternate double-sided laser shock forming was analyzed in this work. The grains are distorted and refined during high strain rate plastic deformation due to dislocation slip and accumulation. The mechanical properties were enhanced by unequal alternate double-sided laser shock forming for harden layers in both panel sides. The harden layers and grain refinement has a great significance in inhibiting the crack generation and growth.
\end{abstract}

Keywords: laser shock forming; laser energy; thin panel thickness; harden layer; grain refinement

\section{Introduction}

To meet the demand for high speed and high quality of aircraft, integral panels with complex structure are widely used in aircraft structures to reduce the weight and assembly time[1]. Due to process limitations, it is difficult for conventional forming method to satisfy the forming accuracy and complex structure. On the other hand, as a main stress components, integral panel plays an important role in the overall stress of aircraft structure. The fatigue life of integral panel is crucial for aircraft safety[2]. It is a great demand for the form processing to make the integral panel form accurately and improve the mechanical properties at the same time.

Roll forming and creep-age forming are the common form methods, but they have poor 
adaptability for the complex structure. As a novel forming method, laser shock forming(LSF) is an accurate cold forming method for thin panel, where the panel curvature is altered by the laser shock wave at room temperature. Different from shot peen forming, LSF can improve the hardened layer depth, and keep surface intact, meanwhile, it is easier to control the forming parameters. In 2002, Hackel[3] firstly found that 3D bending deformation was induced in metal panel by laser shock processing. In 2007, Ocaña[4] found that stainless steel 304 was bent to different directions when treated by laser shock wave. In 2010, $\mathrm{Hu}$ [5] revealed the mechanism of concave and convex deformation. Luo[6] realized the control of complex shape by introducing distributed eigen-moment as an intermediate variable. In LSF, the bending deformation of metal panel is controlled by laser power intensity, overlapping ratio, impact time and impact path. This controllable process parameters can make LSF to be a high-precision forming method in the future, meanwhile, the deformation springback can be inhibited in the cold forming at room temperature, therefore LSF has obvious advantages in metal panel forming, compared with conventional forming processes.

In conventional skin stringer riveted structure, the crack separately propagates on the skin or stringer, since the skin and stringer are separate components. But for integral panels, Li[7] thought that any damage may threatens their service life, and the crack propagation resistance of integral panels is crucial for aircraft safety and performance. The crack propagation resistance and bending forming urgently need to be solved for integral panels. Laser shock processing(LSP) is an advanced surface modification method to enhancing the fatigue property by inducing hardened layer and compressive residual stress. For AISI 4140 steel, Ye[8] used LSP to enhance the bending fatigue strength to $1125 \mathrm{MPa}$. Wang[9] found that the corrosion fatigue property of AISI 420 stainless steel is extended due to microstructure refinement and gradient residual stress induced by laser shock wave. Zhao[10] improved the mechanical properties of titanium alloy treated by LSP in surface residual stress and micro-hardness. Ren[11] estimated the service life of titanium alloy panel treated with double-sided LSP. Ye[12] verified that LSF, as a derivant from LSP, can make thin panel bending toward or away from laser beam, and induce compressive residual stress in the top or bottom surfaces, however, in the surface away from laser beam, the compressive residual stress is too small, and the surface has no harden layer, then the compressive stress can be easily released during service time. In order to guarantee the bending deformation and induce harden layer in both surfaces, this paper proposes unequal alternate double-sided laser shock forming, where a laser beam with low energy is used to modify one side of thin panel, then another side surface is impacted by another laser beam with high energy to make this panel bend with an angle. And the mechanical properties of thin metal panel can be improved by the unequal alternate double-sided laser shock forming.

In this work, the bending degree was obtained by visual inspection system. The residual stress and microhardness were investigated in 7075 aluminum panel before and after unequal alternate double-sided laser shock forming, and the surface morphologies were characterized by white-light interference surface profilometer. The microstructure distribution was tested using electron backscattered diffraction (EBSD) and X-ray Diffraction (XRD). the improvement in mechanical properties and microstructure evolution after unequal alternate double-sided laser shock forming 
was discussed based on theoretical analysis. This work expounds a novel method to form thin panel and improve the mechanical properties.

\section{Materials and methods}

\subsection{Material and specimen}

7075 aluminium alloy is widely used in aerospace field for high strength property. Since panel thickness is one of important parameters for LSF, this work purchases 7075 aluminium panel with uniform thickness from Shanghai Jinxiao Corporation. The chemical compositions of 7075 aluminium alloy used in the experiments are shown in Table 1. In order to analyze the effect of unequal alternate double-sided laser shock forming on mechanical property and microstructure evolution, 7075 aluminium panels with $1 \mathrm{~mm}$ and $3 \mathrm{~mm}$ thickness are used in this work, and the geometric dimension of the panel is $125 \times 25 \mathrm{~mm}$, shown in Fig. 1 .

Table 1 the chemical compositions of 7075 aluminium alloy used in the experiments(wt.\%).

\begin{tabular}{ccccccccc}
\hline $\mathrm{Si}$ & $\mathrm{Fe}$ & $\mathrm{Cu}$ & $\mathrm{Mn}$ & $\mathrm{Mg}$ & $\mathrm{Cr}$ & $\mathrm{Zn}$ & $\mathrm{Ti}$ & $\mathrm{Al}$ \\
\hline $0-0.4$ & $0-0.5$ & $1.2-2.0$ & $0-0.3$ & $2.1-2.9$ & $0.18-0.28$ & $5.1-6.1$ & $0-0.2$ & Balance \\
\hline
\end{tabular}

\subsection{Laser shock forming experiment}

In unequal alternate double-sided LSF experiments, 7075 aluminium panels are formed by a Q-switched Nd: YAG pulsed laser with a spot diameter of $4 \mathrm{~mm}$ and the pulse duration of $15 \mathrm{~ns}$. As Fig. 1 shows, before experiments, one end of the panel is fixed by a fixture. In order to keep each impact along shocking direction, the impacted path starts from the free end to the fixed end. The overlapping is defined as $1 / \mathrm{d}$, set as $50 \%$. In unequal alternate double-sided LSF, the panel firstly is pretreated by a laser beam with low energy $(4 \mathrm{~J})$ on one side, then formed by another laser beam with high laser energy $(8 \mathrm{~J})$ on another side, and the impact path is same. The panels with $1 \mathrm{~mm}$ thickness is induced into concave bending deformation, where the pretreatment surface is marked with A1, the surface shocked by $8 \mathrm{~J}$ laser beam is marked with $\mathrm{A} 2$, and the surface of $1 \mathrm{~mm}$ panel before laser shock is marked with A0. The final $3 \mathrm{~mm}$ thickness panel is bent with convex curvature, where the surface treated by $4 \mathrm{~J}$ laser beam is marked with $\mathrm{B} 1$, the surface shocked by $8 \mathrm{~J}$ laser beam is marked with B2, and the untreated surface of $3 \mathrm{~mm}$ panel is marked with B0.

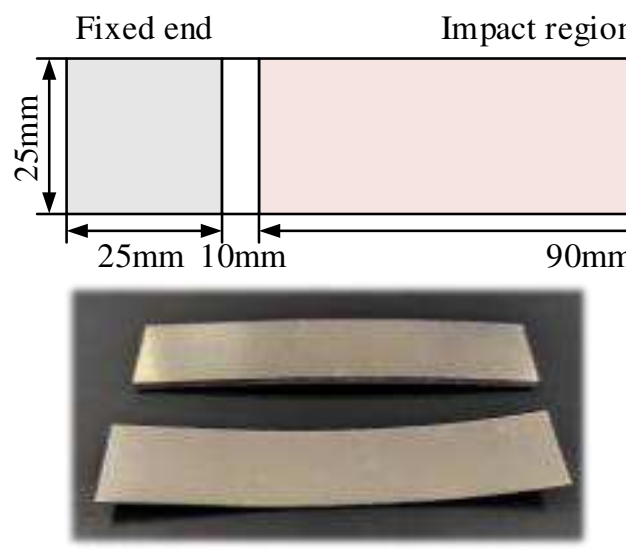

The formed plates
The plate cross section
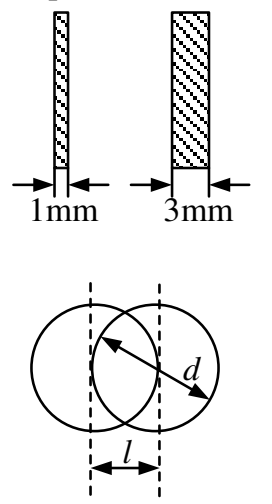

Overlapping ratio

Fig. 1 The geometry of 7075 aluminium panel and laser shock path. 


\subsection{Measurement method}

Visual inspection system for surface manufacturing is an efficient and accurate method for surface defect detection and model reconstruction[13]. In this work, the impact surfaces are detected by three-dimensional hand-held scanner with $1 \mathrm{~mm}$ step size. Positioned by location point, the metal panel is rebuilt by point cloud used to analyze the bending deformation. The center line of the point cloud is used to evaluate the deformation degree, which is picked out by python code. To observe the effect of laser shock wave on panel surface, White-light interference surface profilometer (WLI) is performed to measure the surface morphology and roughness. The metal surface can be hardened under laser shock wave, and the surface and cross section microhardness is detected by Micro-vickers hardness tester (HV1000) with 100g loading for 15s. The final surface hardness is obtained by the test method in Yang's work[14]. The final cross section hardness is decided by the average value of three repeated tests. The residual stress is tested by Proto-LXRD stress measurement system based on $\sin 2 \psi$ method on panel surface before and after unequal alternate double-sided laser shock forming. The collimator diameter is $1 \mathrm{~mm}$, and the range of $2 \theta$ scanning angle is $137^{\circ}-145^{\circ}$. In the measure, the material is removed by the eletropolishing layer by layer. The final residual stress is decided by the average value of three times repeated tests. Besides mechanical property measurement, the microstructure is also analyzed in this work. On the surfaces before and after unequal alternate double-sided LSF, the phase structure and crystal orientation is detected by X-ray Diffraction (XRD)(X' Pert PRO) with a scanning speed of $4 \% \mathrm{~min}$ in $2 \theta$ range from $30^{\circ}-80^{\circ}$. The microstructure in cross section is observed by metallurgical microscope. Before the observation, the cross section of specimen is polished into a mirror, and corroded by chemical etchant. Electron backscattered diffraction (EBSD) is performed to analyze the orientation, boundary and misorientation angle distribution, including a SEM (TESCAN MIRA3, Czech) and an HKL-EBSD system. The surface used into EBSD is electropolished.

\section{Results and discussion}

\subsection{Bending deformation}

The process of unequal alternate double-sided LSF is shown in Fig.2(a) and (b). For 7075 aluminum panels with $1 \mathrm{~mm}$ thickness, the panels bend toward laser beam. The shock wave can propagate to the bottom surface, and the serious plastic with high strain rate leaves a dome pit in the panels, which leads the shock surface bending toward laser beam[15]. For 3mm thickness panel, the stress wave decays to elastic stress wave before the stress wave propagates to bottom surface, and the dome pit almost has no effect on the bending deformation, however, residual stress with a gradient is induced along depth direction, which a driving force of convex bending deformation in the thick panels[5]. In order to estimate the forming ability of unequal alternate double-sided LSF, the panel surfaces are scanned by hand-held scanner to obtain the point cloud and reconstruct the bending model before and after the double-sided LSF, then the center line is picked up from the point cloud of panel surfaces, shown in Fig. 2(c) and (d). As the results show, 1mm thickness panel has a concave deformation, and the maximum displacement of the free end is $15.3 \mathrm{~mm}$. $3 \mathrm{~mm}$ thickness panel is bent with a convex curvature, and the displacement of free end is $-6.02 \mathrm{~mm}$. Therefore, unequal alternate double-sided LSF can retain the great form ability in thin metal panels. 
Besides, the mechanical property and microstructure of 7075 aluminum panel are certainly affected by the unequal alternate double-sided LSF, which will be discussed in next work.
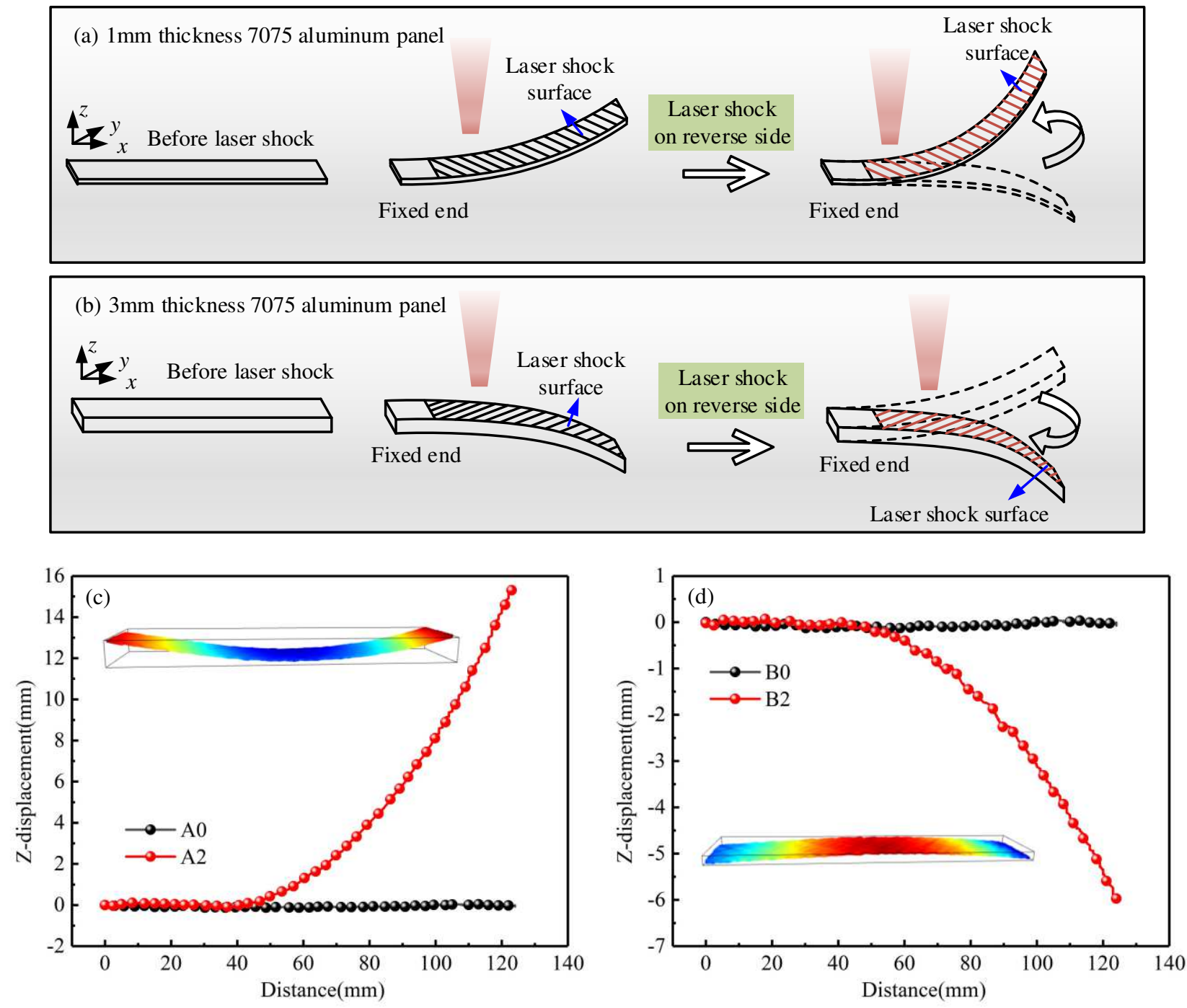

Fig. 2 The process of unequal alternate double-sided LSF and the center line of 7075 aluminum panels with $1 \mathrm{~mm}$ and $3 \mathrm{~mm}$ thickness.

\subsection{Surface morphology}

Compared with shot peening, laser shock processing induces a deeper harden layer on specimen surface, and protects the surface integrity[16]. Surface morphology is used to test the effect of laser shock wave on the panel surface in LSF. In order to obtain the surface roughness and observe the surface texture, curved surface is flattened to a horizontal plane. Fig. 3 shows the surface morphology of $1 \mathrm{~mm} 7075$ aluminum panel before and after unequal alternate double-sided LSF, and the surface morphology of $3 \mathrm{~mm}$ panel is shown in Fig. 4. The observed surface region is set as $12 \mathrm{~mm} \times 12 \mathrm{~mm}$. Fig. 3(c) and Fig. 4(c) show the surfaces impacted by $8 \mathrm{~J}$ laser beam, and another surfaces shocked by $4 \mathrm{~J}$ laser beam are shown in Fig. 3(e) and Fig. 4(e). From Fig. 3(c) and (e), $1 \mathrm{~mm}$ panel has a concave bending deformation after the second laser shock processing with $8 \mathrm{~J}$ energy, which is same as the result in Fig. 2. In the flattened surface, there is some blurry vertical texture on the surface shocked by $8 \mathrm{~J}$ laser beam in Fig. 3(d). Compared with the untreated surface in Fig. 3(b), a slight change can be recognized in Fig. 3(f). Contrary to the deformation of $1 \mathrm{~mm}$ 
panel, 3mm panel shows a convex bending deformation after unequal alternate double-sided LSF, shown in Fig. 4(c) and (e). A clear texture can be seen on B2 surface, which is decided by 50\% overlapping ratio. Similarly, the shock wave formed by $4 \mathrm{~J}$ laser energy has slight effect on $3 \mathrm{~mm}$ panel surface.

The surface roughness calculated in the flattened surface is shown in Fig. 5. Surface roughness of $1 \mathrm{~mm}$ panel before and after unequal alternate double-sided LSF is shown in Fig. 4(a), and that of $3 \mathrm{~mm}$ panel is shown in Fig. 5(b). For the untreated panels, the roughness in $1 \mathrm{~mm}$ panel is higher than that in $3 \mathrm{~mm}$ panel. The surface roughness may be the critical parameter to cause the difference of texture on A2 and B2 surfaces. The surface roughness in A1 raises from 1.019 $\mu \mathrm{m}$ to $1.405 \mu \mathrm{m}$, and that in A2 raises to $1.546 \mu \mathrm{m}$. Fig. 5(b) shows the same trend in $3 \mathrm{~mm}$ panel. The surface roughness increases as raising laser energy, but the surface maintains a great integrity after unequal alternate double-sided LSF.
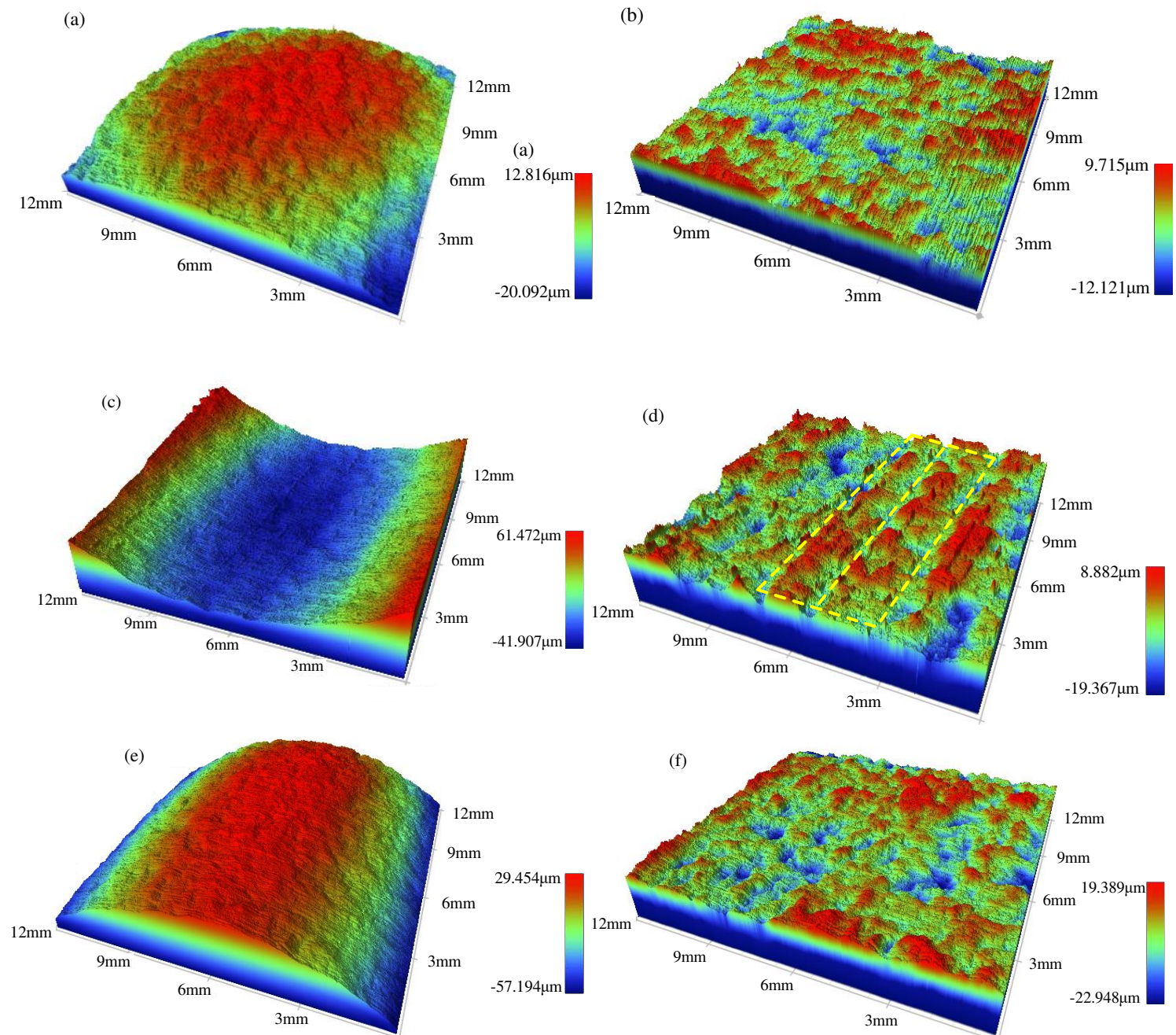

Fig. 3 The surface morphology of $1 \mathrm{~mm} 7075$ aluminum panel before and after unequal alternate double-sided $\operatorname{LSF}((a)$ : the surface of A0; (c): the surface impacted by $8 \mathrm{~J}$ laser energy in A2; (e): the surface impacted by $4 \mathrm{~J}$ laser energy in A1; (b)(d)(f) are the flattened surfaces of (a)(c)(e) separately). 

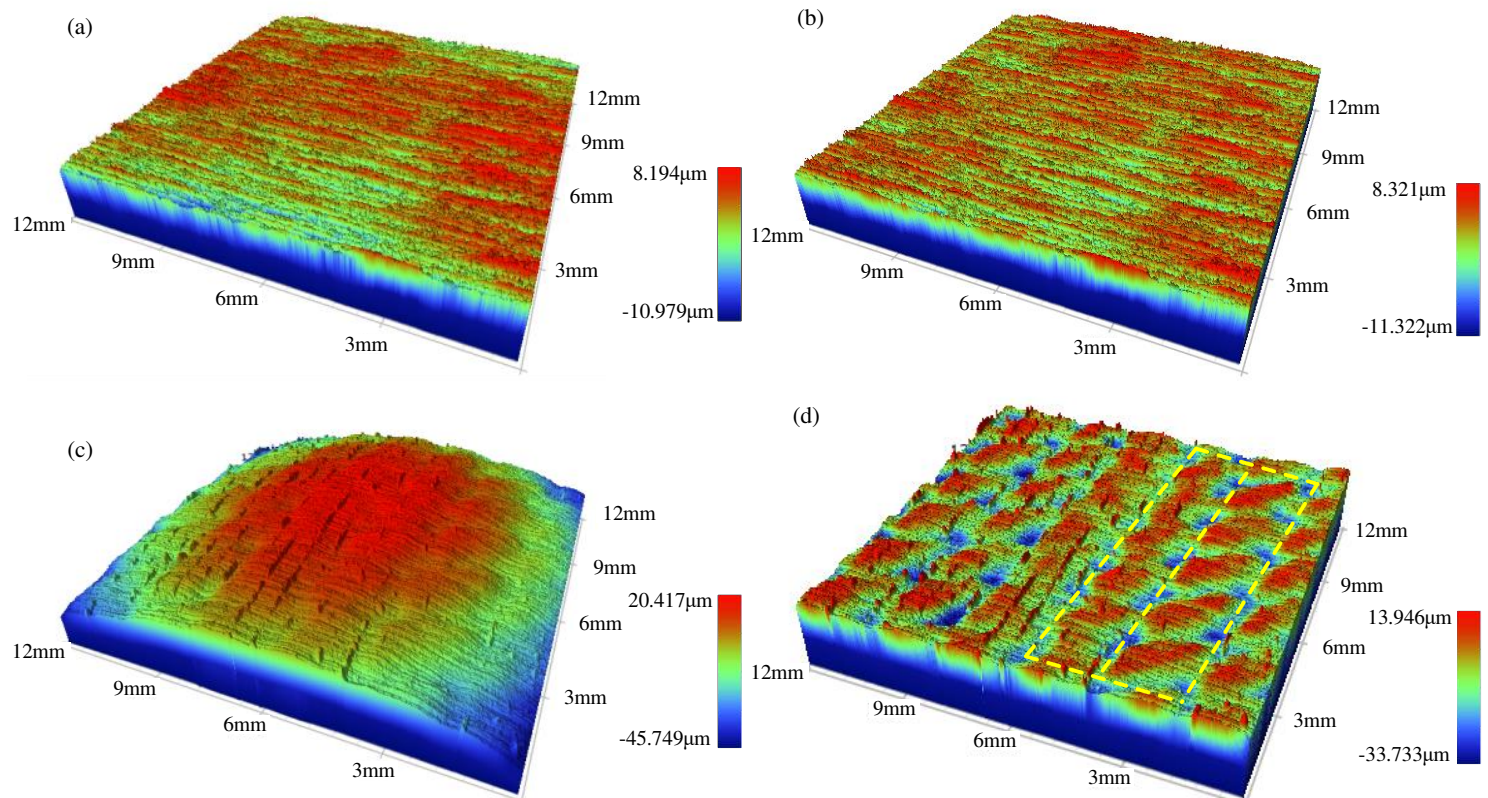

(d)
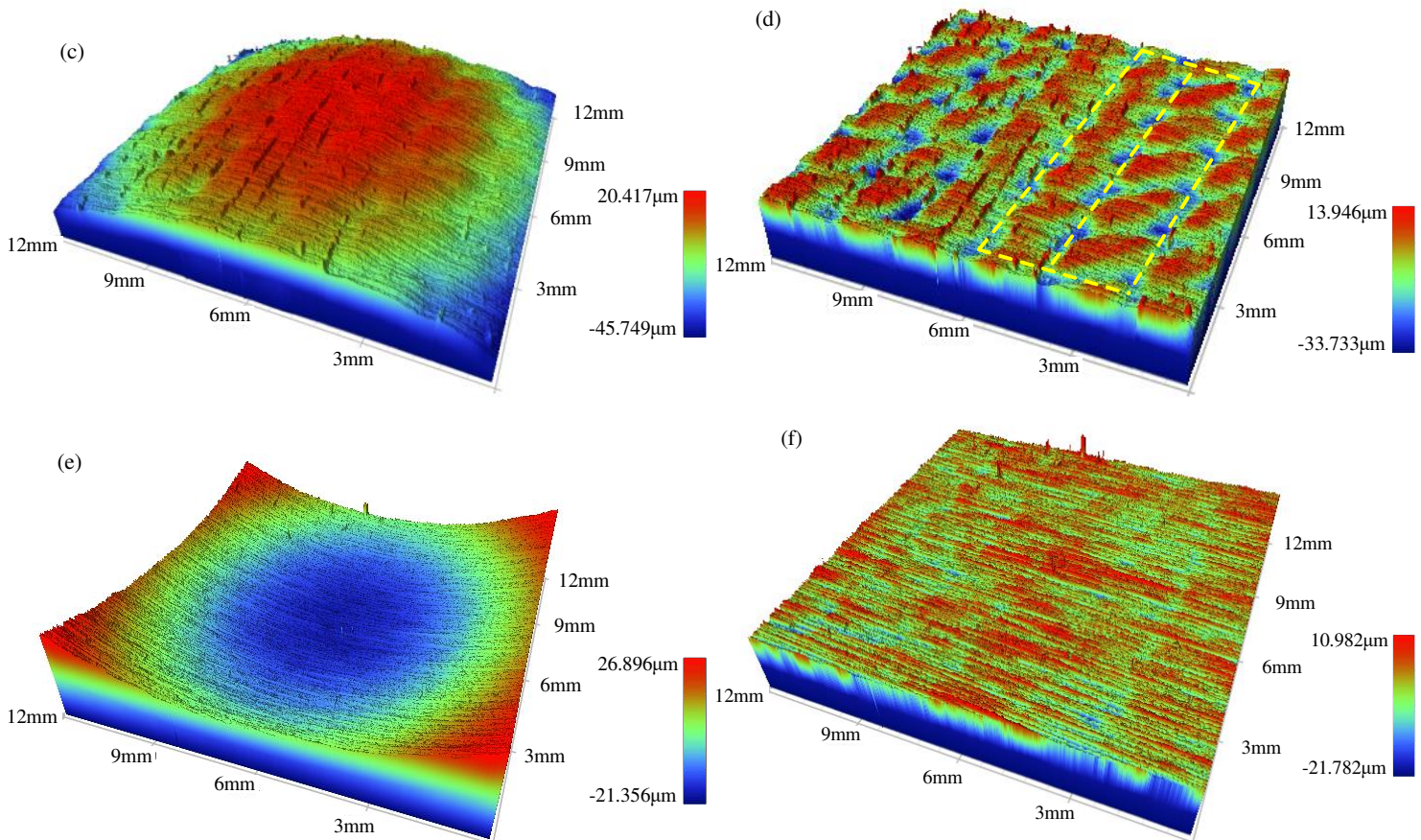

Fig. 4 The surface morphology of 3mm 7075 aluminum panel before and after unequal alternate double-sided LSF ((a): the surface of B0; (c): the surface impacted by 8J laser energy in B2; (e): the surface impacted by $4 \mathrm{~J}$ laser energy in B1; (b)(d)(f) are the flattened surfaces of (a)(c)(e) separately).
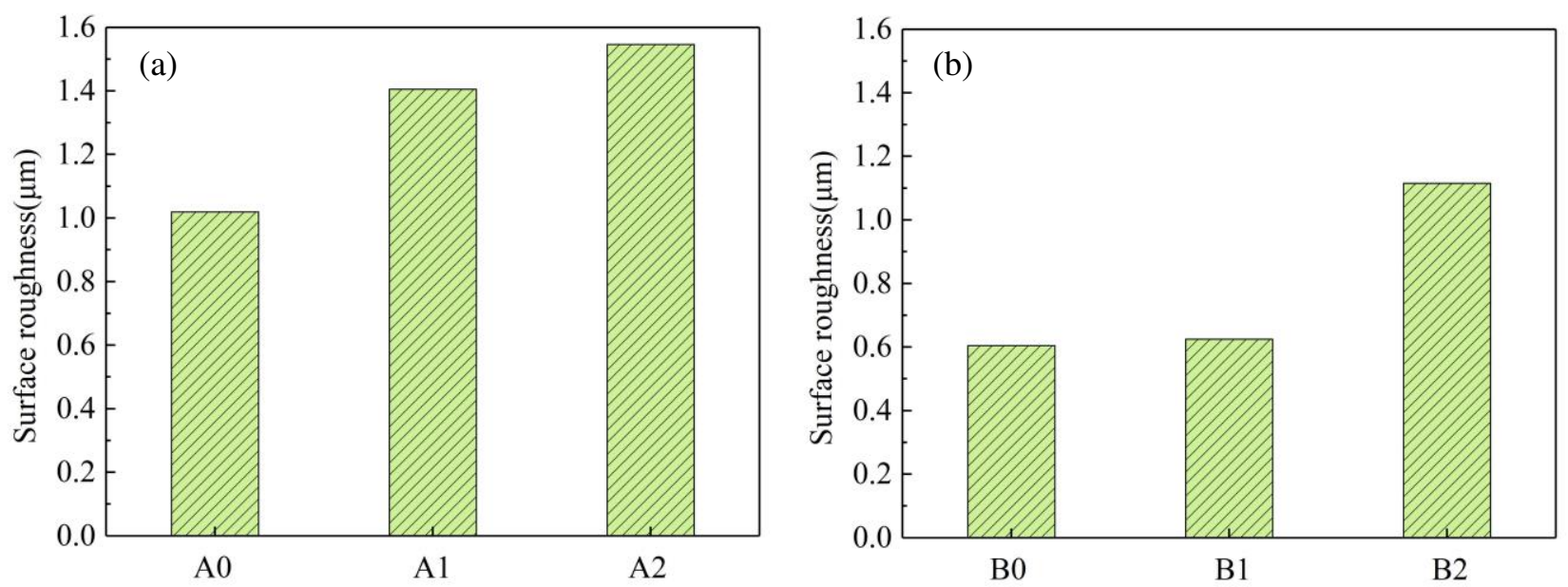

Fig. 5 The surface roughness of $1 \mathrm{~mm}$ (a) and $3 \mathrm{~mm}$ (b) 7075 aluminum panel before and after unequal alternate double-sided LSF.

\subsection{Mechanical property}

The harden layer and compressive residual stress can slow down the rate of crack initiation and propagation in material surface during serve time[8]. Microhardness is one of important parameters 
to evaluate material mechanical properties. Fig. 6 shows the microhardness along depth direction of 7075 aluminum panel before and after unequal alternate double-sided LSF. Before LSF treatment, the microhardnesses of $1 \mathrm{~mm}$ and $3 \mathrm{~mm} 7075$ aluminum panel are about $180 \mathrm{HV}$. Since $1 \mathrm{~mm}$ panel is too thin, the microhardness of the whole section is detected from A2 to A1, shown in Fig. 6(a). For $3 \mathrm{~mm}$ panel, the measured depth is set as $1 \mathrm{~mm}$, shown in Fig. 6(b). Form Fig. 6(a), the microhardnesses in A2 and A1 surfaces are both elevated, and the effected depth is about $0.5 \mathrm{~mm}$. The microhardness of A2 surface is improved from $180 \mathrm{HV}$ to $206.8 \mathrm{HV}$, and that on A1 surface raises to $191.4 \mathrm{HV}$. For $3 \mathrm{~mm}$ panel, the microhardnesses of B2 and B1 are separately $204.6 \mathrm{HV}$ and $198.5 \mathrm{HV}$, and the surface microhardness would increase when laser energy rises. The depth of harden layers are $0.2-0.6 \mathrm{~mm}$ in $1 \mathrm{~mm}$ and $3 \mathrm{~mm}$ thickness panel surfaces. Therefore, under the action of laser shock wave, harden layers are induced into both panel surfaces by unequal alternate doublesided LSF[17]. The improvement in microhardness could be a reaction of the microstructure evolution in 7075 aluminum panel, which would be analyzed in future discussion, based on the results from XRD and EBSD.
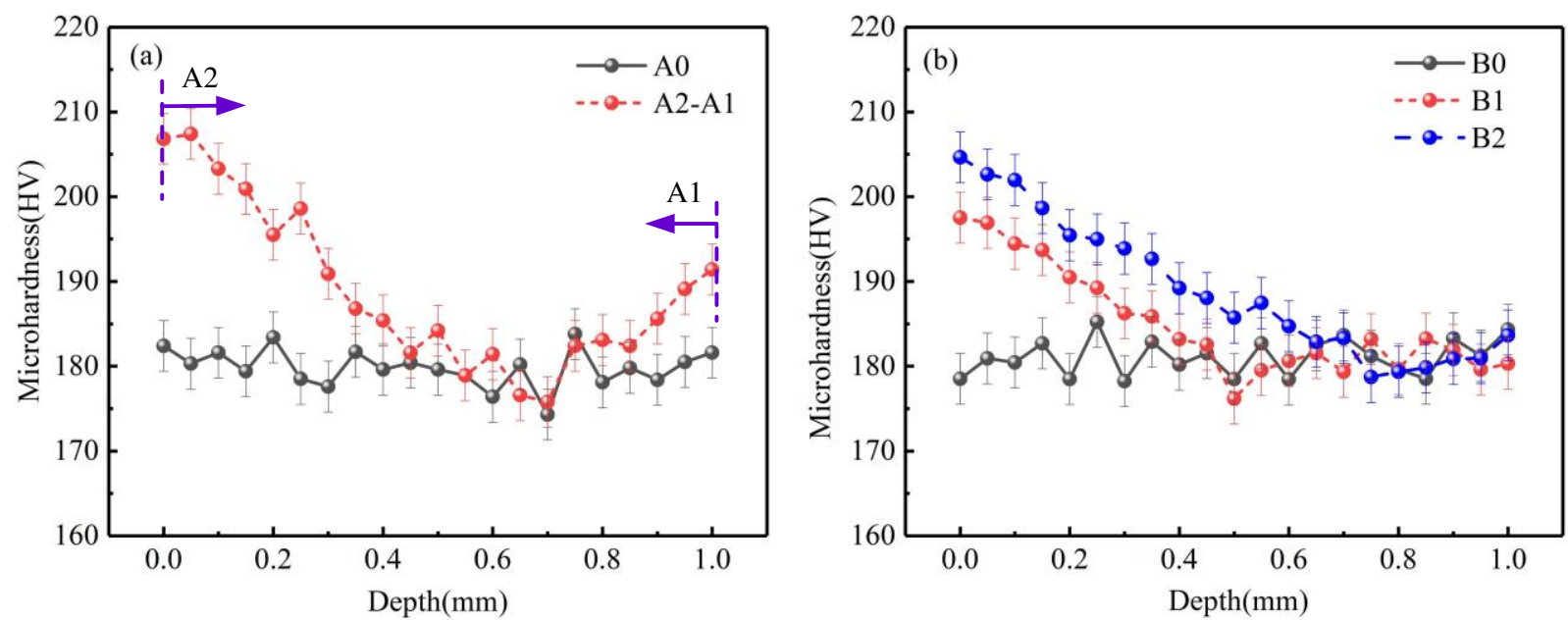

Fig. 6 The microhardness along depth direction of $1 \mathrm{~mm}$ (a) and 3mm(b) 7075 aluminum panel before and after unequal alternate double-sided LSF.
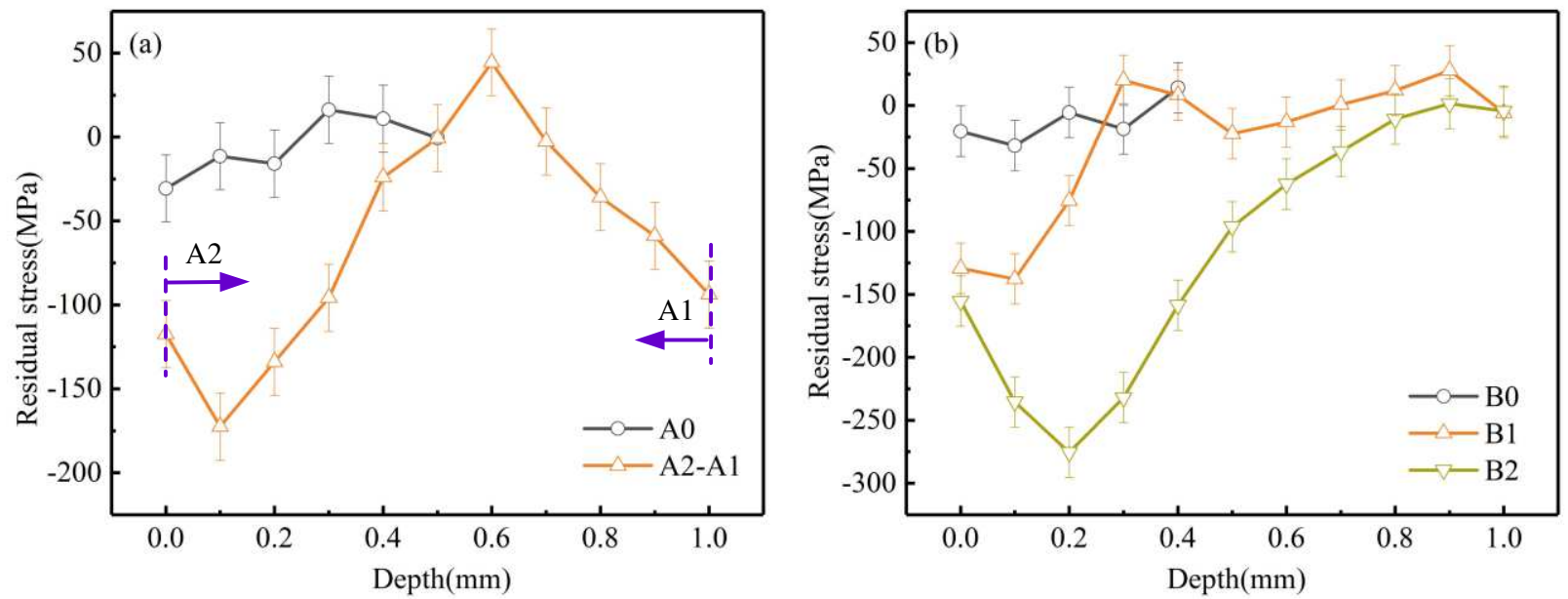

Fig.7 The residual stress along depth direction of $1 \mathrm{~mm}$ (a) and 3mm(b) 7075 aluminum panel before and after unequal alternate double-sided LSF.

Fig. 7 presents the residual stress along depth direction of $1 \mathrm{~mm}$ and $3 \mathrm{~mm} 7075$ aluminum 
panels before and after unequal alternate double-sided LSF. The untreated surface has a small compressive residual stress caused by the rolling process and grinding. Since the $3 \mathrm{~mm}$ panel is too thick, the in-depth residual stress in the panel is divided into two parts, and the first test point is set on surface B1 or B2. The compressive residual stresses are induced into double side surfaces of aluminum panels by unequal alternate double-sided LSF. Started from A1 or B1 surfaces, the residual stress decreases as the depth increases, and the stress increases and decreases as the depth increases near A2 or B2 surfaces. Under $4 \mathrm{~J}$ laser beam, the maximum residual stress is located on the surface. The residual stress of A1 and B1 reached -94 and $-109 \mathrm{MPa}$, respectively. Under the shock wave excited by $8 \mathrm{~J}$ laser beam, the distribution of residual stress along depth presents a hook shape, and the maximum residual stress lies in subsurface layer, that is -173 and $-275 \mathrm{MPa}$ under A2 and B2 surface, respectively. The increase in compressive residual stress could be discussed by the microstructure evolution induced by unequal alternate double-sided LSF[18].

\subsection{XRD analysis}

$\mathrm{XRD}$ is used to analyze the chemical composition and molecular structure to determine the crystal structure[19]. Under the effect of laser shock wave, the high strain plastic deformation induces grain refinement and distortion, and the diffraction peaks shift in XRD can be used as an evidence of lattice distortion in material interior[20]. Fig. 8 shows the X-ray diffraction patterns of $1 \mathrm{~mm}$ panel surface before and after unequal alternate double-sided LSF, and Fig. 9 shows that of $3 \mathrm{~mm}$ panel surface before and after unequal alternate double-sided LSF. Fig. 8(a) and Fig. 9(a) show the whole diffraction patterns from $30^{\circ}$ to $80^{\circ}$. The results show that four lattice plane has been detected, including $(1,1,1),(2,0,0),(2,2,0)$ and $(3,1,1)$. The type of lattice plane and peak position are same with the results of Zhou's work[21]. There is no new peak after laser impact, indicating no new phase is induced into $1 \mathrm{~mm}$ or $3 \mathrm{~mm} 7075$ aluminum panel and the crystal structure is not changed by laser shock wave. The four peak in $1 \mathrm{~mm}$ panel are compared individually in Fig. 8(b), (c), (d) and (e). Compared with A0, the peak intensity of $(1,1,1),(2,2,0)$ and $(3,1,1)$ in $\mathrm{A} 1$ has a great change, but there nearly is no diffraction peaks shift, implying that the shock wave induced by $4 \mathrm{~J}$ laser energy urges a conversion between different phases, and there is almost no lattice distortion. In A2, every peak intensity has been changed by the effect of laser shock wave, and diffraction peaks shift a small angle to the left. There is the conversion between different phases and lattice distortion on A2 surface. The four peaks in $3 \mathrm{~mm}$ panel are listed in Fig. 9(b), (c), (d) and (e). Compared with the peaks in B0 surface, there is a few difference between the peak intensity in B1 and B2 surfaces, but all diffraction peaks shift a small angle to the left. Therefore, the lattice is distorted by the laser shock wave in $3 \mathrm{~mm}$ panel surfaces. The lattice distortion is contributed to the residual stress distribution in the surface and subsurface layer of the formed panels[20][22].

The full width at half maximum (FWHM) of diffraction peak (111), (200), (2,2,0) and $(3,1,1)$

are listed in Table 2. Compared with A0, FWHM of the four diffraction peaks are broadened after LSF in both side surface, and high laser energy would urge FWHM to increase. The same regular result can also be found in $3 \mathrm{~mm} 7075$ aluminum panel. In general, the peak broadening is caused by the grain refinement, lattice deformation and micro strain development[23]. Under the effect of 
laser shock wave, high strain plastic deformation promotes the dislocation slip and accumulation[24], which is attributed to the grain refinement, and some micro strains are induced into surface layer. Hence, FWHM increasing can be qualitatively used as an evidence of grain refinement and lattice distortion in unequal alternate double-sided LSF.
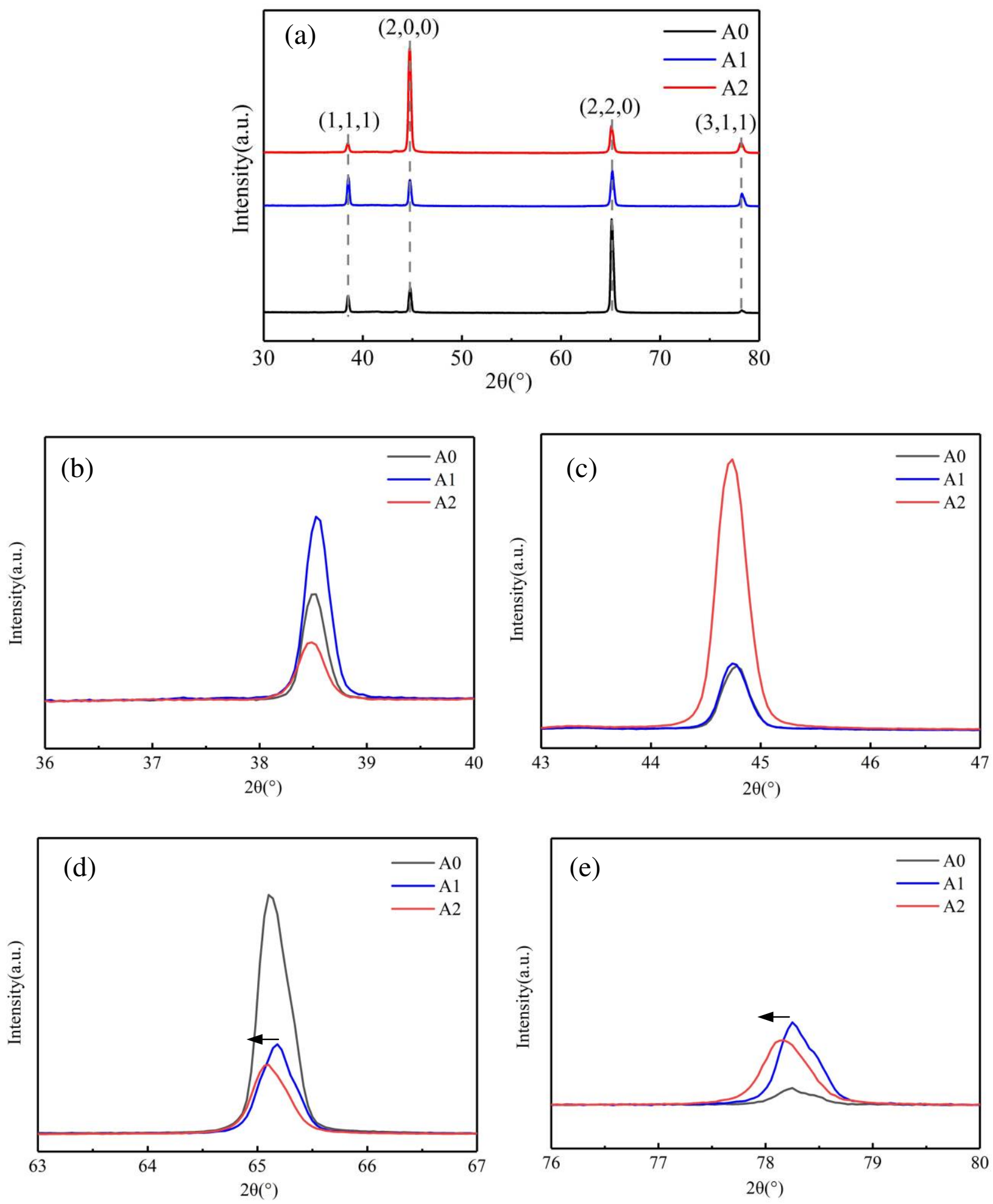

Fig. 8 X-ray diffraction patterns of $1 \mathrm{~mm}$ panel surface before and after unequal alternate double-sided LSF. 

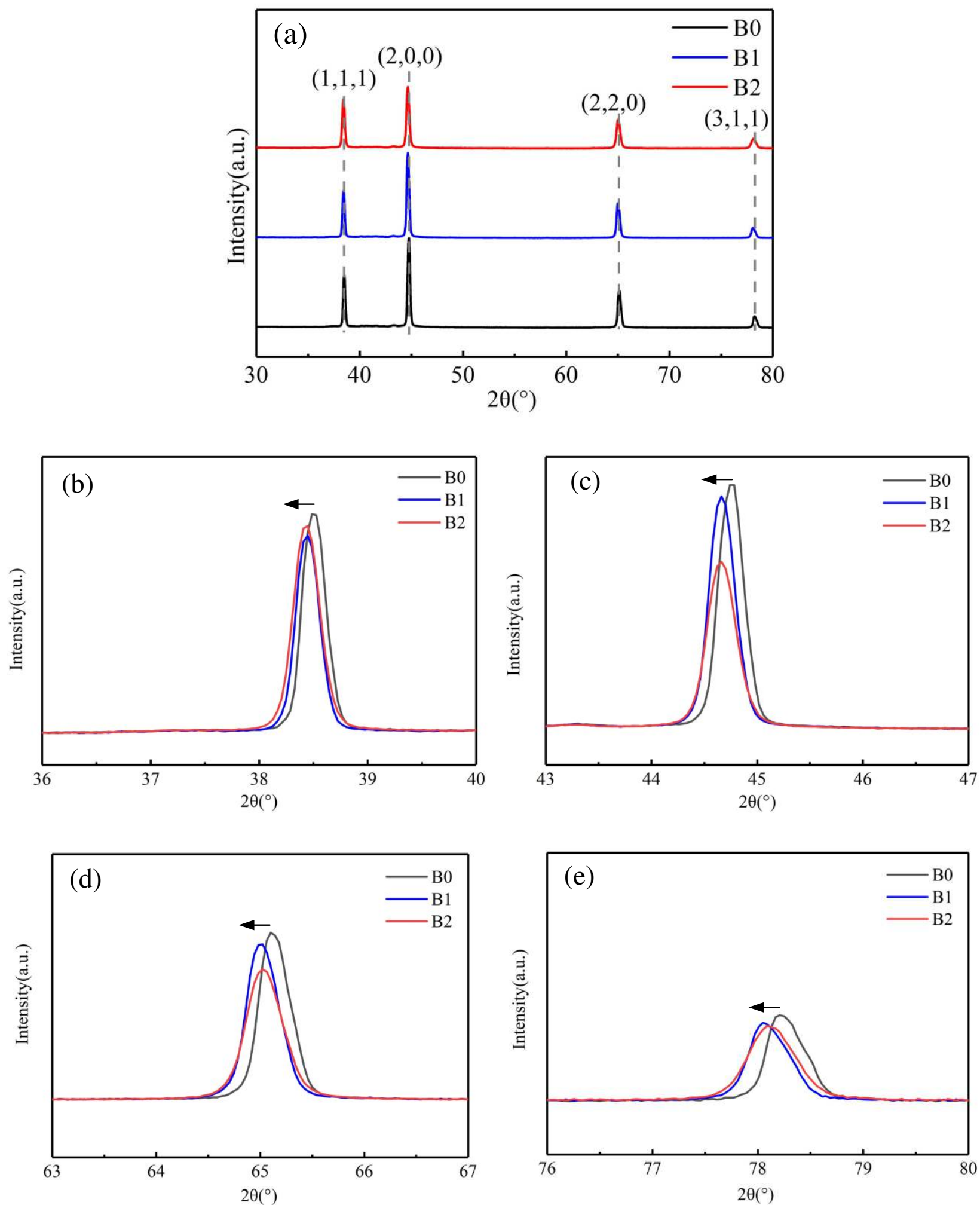

Fig. 9 X-ray diffraction patterns of $3 \mathrm{~mm}$ panel surface before and after unequal alternate double-sided LSF. 
Table 2 FWHW of the diffraction peak (111), (200), (2,2,0) and $(3,1,1)$ in 7075 aluminum panel before and after unequal alternate double-sided LSF.

\begin{tabular}{ccccc}
\hline Panel & $(1,1,1)$ & $(2,0,0)$ & $(2,2,0)$ & $(3,1,1)$ \\
\hline A0 & 0.2378 & 0.2816 & 0.3271 & 0.4251 \\
A2 & 0.2592 & 0.2861 & 0.3749 & 0.4286 \\
B0 & 0.2950 & 0.3149 & 0.3820 & 0.4915 \\
B1 & 0.2461 & 0.2741 & 0.3448 & 0.4205 \\
B2 & 0.2518 & 0.2866 & 0.3643 & 0.4529 \\
\hline
\end{tabular}

\subsection{Cross-sectional microstructure morphology by EBSD}

Under the effect of shock wave, the microstructure is refined for the dislocation slip and accumulation, which is beneficial to the resistance in residual stress relaxation and crack propagation[25]. Fig. 10 exhibits the cross-sectional electron backscattered diffraction(EBSD) morphology of $1 \mathrm{~mm} 7075$ aluminum panel containing A1(the upper surface in Fig. 10(a)) and A2(the bottom surface in Fig. 10(a)) surfaces. From Fig. 10(a), (b) and (d), compared with the microstructure near A1 surface, the columnar grains are refined by high shock pressure near A2, and the grains in intermediate layer are elongated for the macroscopic pit deformation. In $1 \mathrm{~mm}$ thickness panel, the depth of grain refined layer is more than $0.5 \mathrm{~mm}$, so the grains in intermediate layer are compressed into slim shape for the duplicate effect of $4 \mathrm{~J}$ and $8 \mathrm{~J}$ laser impact in the two surfaces. Kernel average misorientation (KAM) map can qualitatively reflect the homogenization degree of plastic deformation. The high value means the severe plastic deformation or the high defect density, which presents the stress distribution in the deformation. From Fig. 10(d), the cross section has lager stress, especially near surfaces and intermediate layer, since the shock wave can spread through the entire panel and reflect back[26], on the other hand, the intermediate layer may experiences two times action of shock waves. From IPF and pole figure in Fig. 10(b) and (c), the grains in $1 \mathrm{~mm}$ panel have no obvious orientation, and the material is isotropy. Fig. 10(e) shows the boundary misorientation angle distribution in the cross section. The misorientation angle range is $0-$ $3^{\circ}$, belonging to low-angle boundary(LAB). The fraction of deformed grain is $11.77 \%$, shown in Fig. 10(f). The boundary misorientation angle and deformed grain are attributed to the dislocation slip and recombination.

Since $3 \mathrm{~mm}$ panel is too thick, the microstructure in the panel cross section is separated to two parts: the cross-sectional EBSD morphology of the panel near B2 surface is exhibited in Fig.11, and that near B1 surface is shown in Fig. 12. Due to the difference of manufacturing process, the grain sizes in $1 \mathrm{~mm}$ and $3 \mathrm{~mm}$ panel are different. Compared Fig. 11(a) with Fig.12(a), the surface grains are more refined under B2. The degree of grain refinement increases with laser energy rising, and the refinement decreases along the depth direction. Compared with Fig. 12(d), the stress in B2 surface and subsurface is generally higher than that of B1. The residual stress can be elevated with laser energy increasing. Under the interaction of high strain rate and stress, the grains are distorted in B2 and B1 surface and subsurface, and the deformed fraction in Fig. 11(f) is higher than that in 
Fig. 12(f). From Fig. 11(e) and Fig. 12(e), the boundary misorientation angle of B2 surface and is in the range of $0-2^{\circ}$, and that of $\mathrm{B} 1$ surface and is in the range of $0-1^{\circ}$, indicating that laser shock wave induces residual stress into material surface and subsurface, along with grain distortion. According to the above results, the harden layers are induced into both panel surface after unequal alternate double-sided LSF, which plays a significant role in improving the fatigue life of thin metal panel.
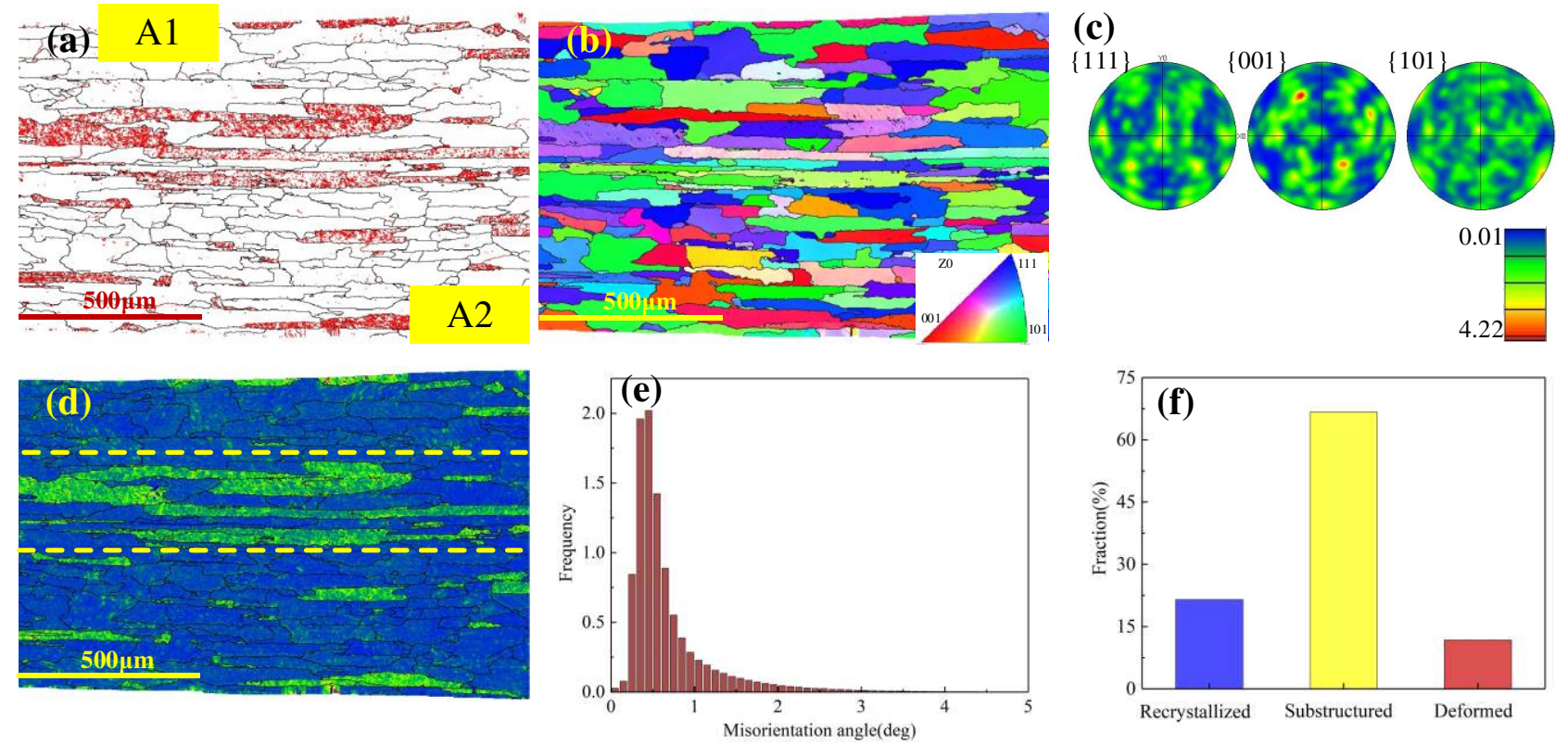

Fig. 10 Cross-sectional EBSD morphology of 1mm thickness 7075 aluminum panel. (a)grain boundary distribution in the cross section; (b)IPF figure of the cross section; (c)pole figure of the cross section; (d)kernel average misorientation (KAM) map in the cross section; (e)boundary misorientation angle distribution in the cross section; (f)deformed fraction in the cross section.
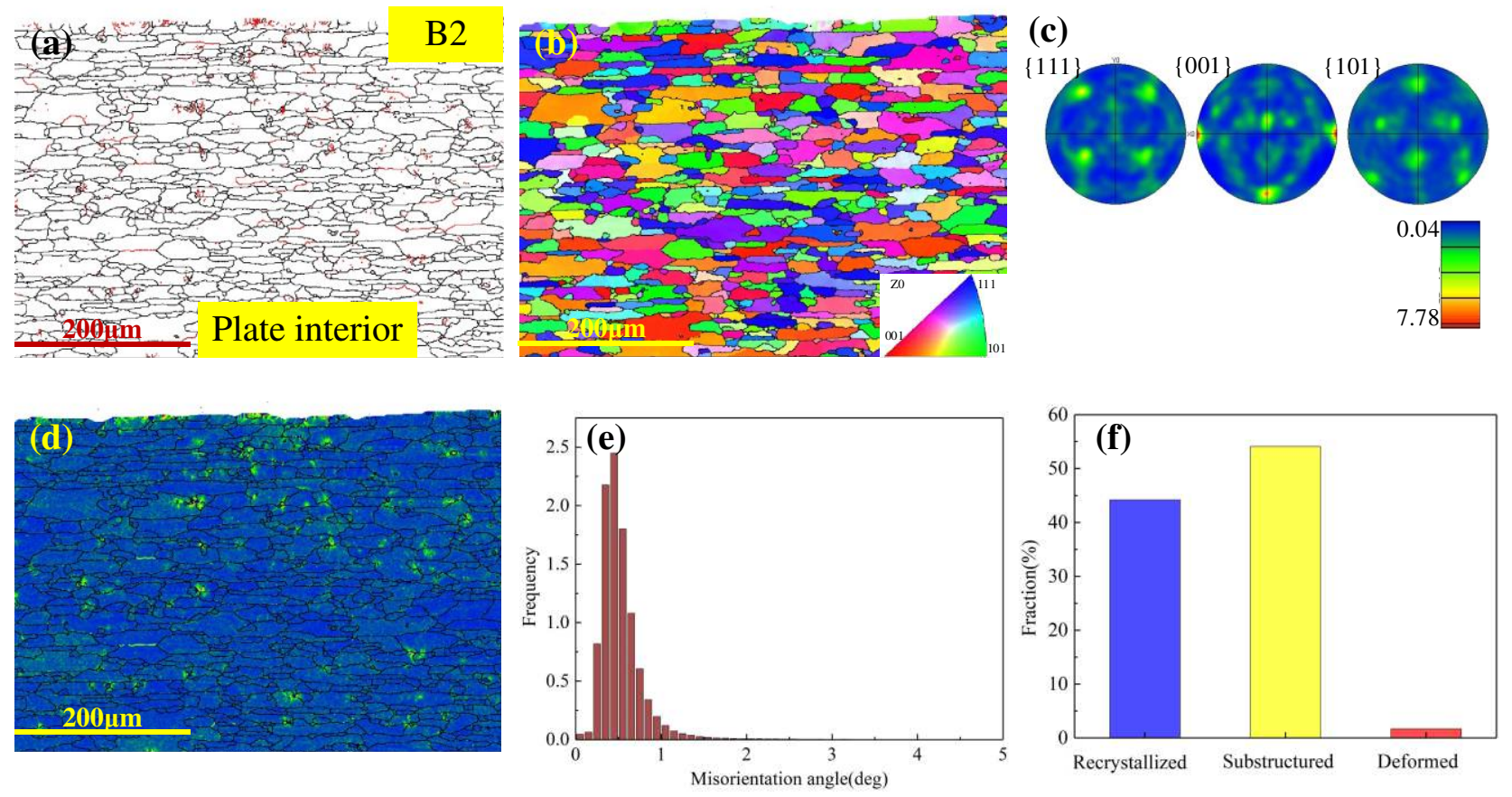

Fig. 11 Cross-sectional EBSD morphology of 3mm thickness 7075 aluminum panel near B2 surface. (a) grain boundary distribution in the cross section; (b) IPF figure of the cross section; (c) pole figure of the cross section;

(d) KAM map in the cross section; (e) boundary misorientation angle distribution in the cross section; (f) deformed fraction in the cross section. 

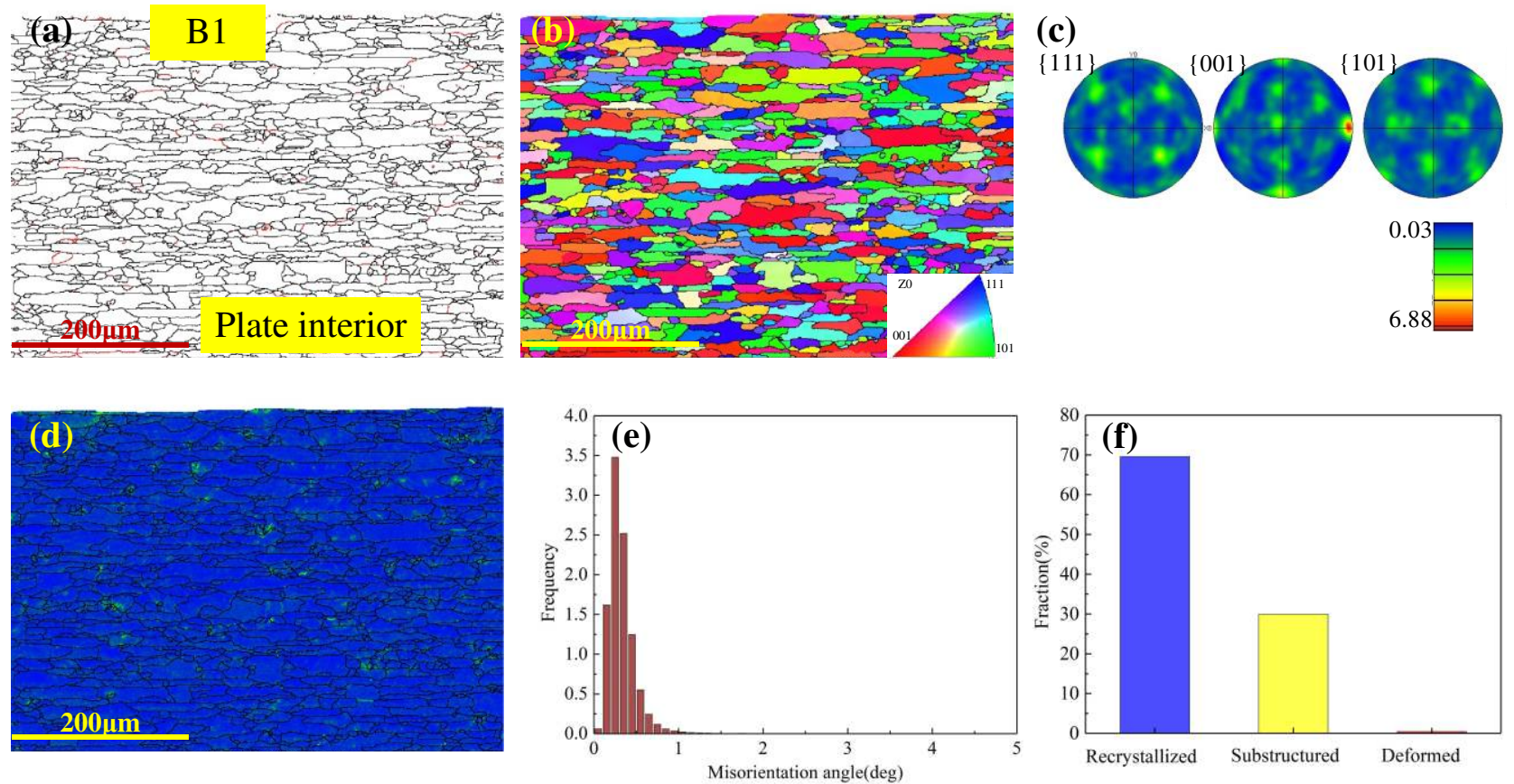

Fig. 12 Cross-sectional EBSD morphology of 3mm thickness 7075 aluminum panel near B1 surface.(a) grain boundary distribution in the cross section; (b) IPF figure of the cross section; (c) pole figure of the cross section;

(d) KAM map in the cross section; (e) boundary misorientation angle distribution in the cross section; (f) deformed fraction in the cross section.

\subsection{The mechanism of unequal alternate double-sided LSF}
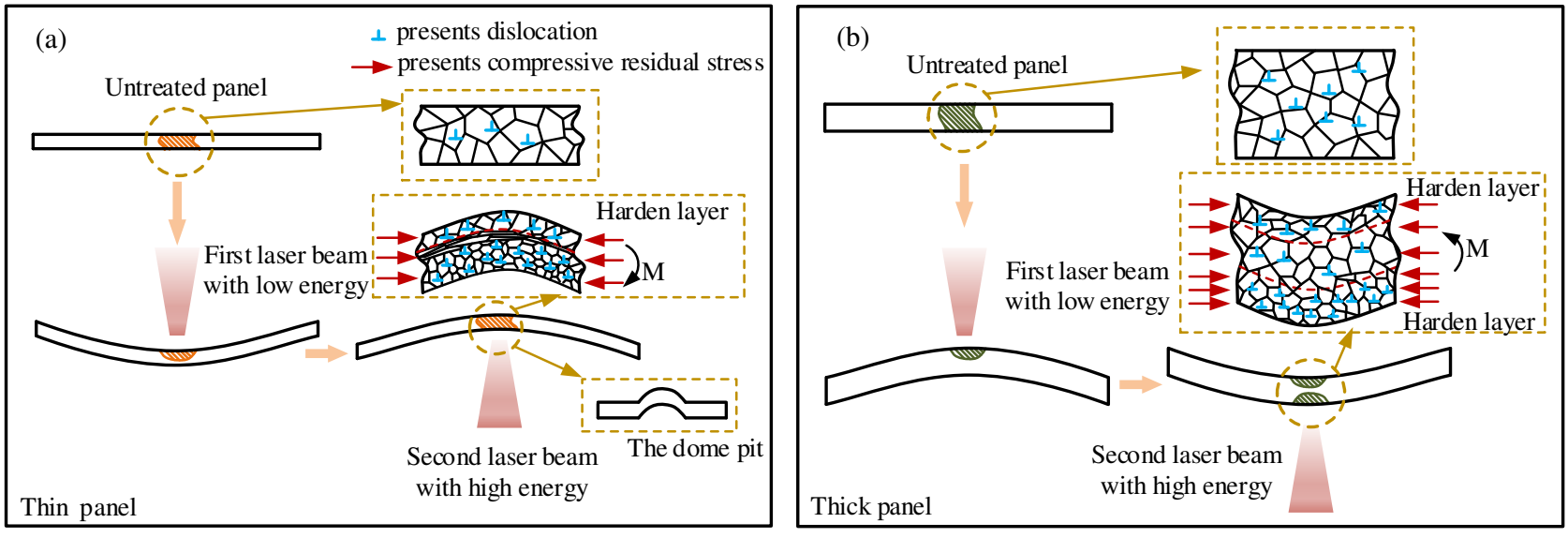

Fig. 13 Mechanism schematics of unequal alternate double-sided LSF.

The bending deformation, improvement in mechanical property and microstructure evolution of 7075 aluminum panel formed by unequal alternate double-sided LSF are analyzed in the paper, and the mechanism schematics of unequal alternate double-sided LSF is summarized in Fig. 13. In the thin panel, the shock wave can travel through the panel, and the plastic deformation is induced in the limited impacted region for the downward inertia of shock loading. Under the shock loading, thin panel is bent toward laser beam due to the geometry compatibility. In thick panel, the plastic deformation region is limited in surface and subsurface, and the stress wave is attenuated in material until to disappearance, so the residual stress decreases along the depth direction with a gradient. A negative bending moment $\mathrm{M}$ imported by the stress gradient drives a convex deformation in thick panel[5]. In unequal alternate double-sided LSF, laser beam with low energy is used to induce a 
harden layer in one panel side, even though a small bending deformation is led into panel at same time. Then the laser beam with high energy is applied on another panel side to bend the panel to the expected shape, and induces another harden layer in the side(shown in Fig. 13).

Under the action of shock wave, high strain rate plastic deformation occurs on material surface. With the increase of propagation distance, the plastic wave gradually changes into elastic wave. At this time, the depth of plastic deformation layer reaches the maximum, which is related to the peak shock pressure and material properties, which can be estimated as follows[27]:

$$
L_{p}=\left(\frac{C_{e l} C_{p l} \tau}{C_{e l}-C_{p l}}\right)\left(\frac{P-\sigma_{H E L}}{2 \sigma_{H E L}}\right)
$$

where $C_{e l}$ and $C_{p l}$ are respectively the elastic and plastic wave velocities in material, $\tau$ is the shock wave duration, $P$ is the peak shock pressure, $\sigma_{H E L}$ is the elastic limit stress of material. After laser shock processing, the surface residual stress is calculated by Fabbro and Peyre, shown as[28]:

$$
\sigma_{\text {surf }}=\sigma_{0}-\left[\mu \varepsilon_{p}(1+v) /(1-v)+\sigma_{0}\right]\left[1-\frac{4 \sqrt{2}}{\pi}(1+v) \frac{L_{p}}{r \sqrt{2}}\right]
$$

where $\sigma_{0}$ is the surface initial residual stress, $\mu$ is Raman coefficient, $v$ is Poisson's ratio, $\varepsilon_{p}$ is plastic strain, $r$ is laser spot radius.

As observed from the cross-sectional microstructure morphology by EBSD, the stress distribution can be distinguished in KAM map, and the distorted grains are marked in grain boundary distribution map. The grain rearrangement is activated during the high strain rate plastic deformation, leading to the grain distortion and refinement(Fig. 13). According to the theories of Johnston and Gilman[29], dislocation density is proportional to plastic strain, indicating that dislocation density increases when plastic strain is improved. During shock process, the plastic strain layer experiences high strain rate plastic deformation, and a large number of dislocations accumulated and tangled, producing dislocation walls and dislocation cells. Due to high strain rate, dislocations are easy to slip and promote grain refinement. When there are high density dislocations in material, the macroscopic performance is work hardening. In Bailey-Hirsch[30] model, the hardness can be estimated as:

$$
H V=H V_{0}+\alpha G b \sqrt{\rho}
$$

where $H V_{0}$ is the material initial hardness, $\alpha$ is a constant about material, $G$ is the shear modulus, $b$ is the Burgers vector, and $\rho$ is the dislocation density. On the other hand, according to Hall-Petch[31] theory, the work hardening of materials is also related to grain size,

$$
H V=H V_{0}+\frac{K_{H V}}{\sqrt{d}}
$$

where $K_{H V}$ is a coefficient of work hardening, $d$ is the grain size. Grain refinement can also harden the material, so the improvement of material mechanical properties and work hardening come from dislocation strengthening and grain refinement strengthening, which inhibits the crack generation and growth.

\section{Conclusions}

The bending behavior of 7075 aluminum panel by unequal alternate double-sided LSF is 
analyzed in this work. The mechanical properties and microstructure evolution in panel surface are investigated. The conclusions are summarized as follows:

(1) In unequal alternate double-sided LSF, the first laser beam with low energy is used to modify one panel surface, then the panel is formed by laser beam with high energy at another surface. The unequal alternate double-sided LSF has a great ability in panel forming and both side surfaces are strengthened by the two laser beams.

(2) The surface texture after laser impact is effected by the laser energy and surface roughness. The texture depth would increases while laser energy rises, and the texture is clear and complete if the surface roughness is small.

(3) In unequal alternate double-sided LSF, the laser energies are different, which are directly related to the distribution of residual stress. For $1 \mathrm{~mm}$ panel, the maximum residual stresses in both side surface are respectively-94 and $-173 \mathrm{MPa}$, and that corresponding residual stresses in $3 \mathrm{~mm}$ panel are $-109 \mathrm{MPa}$ and -275MPa.

(4) The mechanical properties in both sides of thin panel are improved by unequal alternate doublesided LSF. The depth of harden layers are $0.2-0.6 \mathrm{~mm}$ in $1 \mathrm{~mm}$ and $3 \mathrm{~mm}$ thickness panel surfaces.

(5) The results and analysis about mechanical property and microstructure in 7075 aluminum panel indicates that the panels can be formed and strengthened by unequal alternate double-sided LSF. The improvement of residual stress and microhardness comes from the high dislocation density and grain refinement.

\section{Ethical Approval}

This work dose not involve the human ethical issues. And we promise to follow the COPE guidelines on how to deal with potential acts of misconduct.

\section{Consent to Participate}

All authors consent to participate this work.

\section{Consent to Publish}

All authors have agreed to publish this manuscript.

\section{Authors Contributions}

Jiaqi He: preparation of samples. Ying Lu and Boyu Sun: measurements of experiment data. Hongchao Qiao: Comment and revision for the paper. Jibin Zhao: formulations of the problem. Yuqi Yang: summarization of the experiments, writing original paper.

\section{Funding}

This work was sponsored by the National Natural Science Foundation of China (51875558) and the NSFC-Liaoning Province United Foundation of China (U1608259).

\section{Competing interest}

The authors declare that they have no known competing financial interest or personal relationships that could have appeared to influence the work reported in this paper.

\section{Availability of data and materials}

The data that support the findings of this study are available from the corresponding author upon reasonable request. 


\section{Reference}

[1] Xiao H, Zhang S H, Liu J S, et al. Experimental and Numerical Investigation on Filling Roll Bending of Aluminum Alloy Integral Panel[J]. Journal of Manufacturing Science and Engineering, 2012, 134(6); 061011.

[2] Yu K J, Li Y, Jiao L. Study on Strength Assessm ent of Crack Dam age for Integral Panel of an Aircraft[J]. Equipment environmental engineering, 2007, 4(4):31-33.

[3] Hackel L, Harris F. Contour forming of metals by laser peening:US,6410884B1[P]. 2002-06-25.

[4] Ocaña J L, Morales M, Molpeceres C, et al. Short pulse laser microforming of thin metal sheets for MEMS manufacturing[J]. Applied Surface Science, 2007, 254(4): 997-1001.

[5] Hu Y X, Xu X X, Yao Z Q, et al. Laser peen forming induced two way bending of thin sheet metals and its mechanisms[J]. Journal of Applied Physics, 2010, 108(7): 073117-073117-7.

[6] Luo M S, Hu Y X, Hu L, et al. Efficient process planning of laser peen forming for complex shaping with distributed eigen-moment[J]. Journal of Materials Processing Technology, 2020, 279, 116588.

[7] Li Y Z, Zhang X. An Analysis of Fail-Safety and Fracture Control of Integrally Stiffened Panels[J]. Acta Aeronautica et astronautica sinca, 2006, 27(5): 842-846.

[8] Ye C, and Suslov S, Kim B J et al. Fatigue performance improvement in AISI 4140 steel by dynamic strain aging and dynamic precipitation during warm laser shock peening[J]. Acta Materialia, 2011, 59(3):10141025.

[9] Wang C Y, Luo K Y, Bu X Y, et al. Laser shock peening-induced surface gradient stress distribution and extension mechanism in corrosion fatigue life of AISI 420 stainless steel[J]. Corrosion Science, 2020, 177(143611):109027.

[10] Zhao J B, Wu J J, Hu X L, et al. Effect of laser shock processing on mechanical properties of Ti-45.5Al-2Cr2Nb-0.15B alloy[J]. Optik - International Journal for Light and Electron Optics, 2020, 217:164715.

[11] Ren X D, Chen B Q, Jiao J F, et al. Fatigue behavior of double-sided laser shock peened Ti-6Al-4V thin blade subjected to foreign object damage[J]. Optics \& Laser Technology, 2020, 121, 105784.

[12] Ye Y X , Cao X , Zeng R , et al. Characteristics of stress distribution within the metal sheet bent by laser shock forming[J]. Materials Research Express, 2019, 6(9).

[13] Xia R B, Zhao J B, Zhang T Y, et al. Detection method of manufacturing defects on aircraft surface based on fringe projection[J]. Optik - International Journal for Light and Electron Optics, 2020:164332.

[14] Yang Y Q, Lu Y, Qiao H C, et al. The effect of laser shock processing on mechanical properties of an advanced powder material depending on different ablative coatings and confinement medias[J]. The International Journal of Advanced Manufacturing Technology, 2021:1-9.

[15] Cheng G J, Pirzada D, Ming Z. Microstructure and mechanical property characterizations of metal foil after microscale laser dynamic forming[J]. Journal of Applied Physics, 2007, 101(6):345-360.

[16] Qiao H C, Hu X L, Zhao J B, et al. Influence Parameters and Development Application of Laser Shock Processing[J]. Surface Technology, 2019, 48(12):1-9.

[17] Wu J J, Liu X J, Zhao J B, et al. Online Detection Method of Laser Shock Peening Based on Shock Wave Signal Energy in Air[J]. Surface Technology, 2019, 48(10):100-106.

[18] Gill A, Telang A, Mannava S R, et al. Comparison of mechanisms of advanced mechanical surface treatments in nickel-based superalloy[J]. Materials Science \& Engineering A, 2013, 576: 346-355.

[19] Kaschel F R, Vijayaraghavan R K, Mcnally P J, et al. In-situ XRD study on the effects of stress relaxation and phase transformation heat treatments on mechanical and microstructural behaviour of additively manufactured Ti-6Al-4V[J]. Materials Science and Engineering A, 2021(3):141534.

[20] Guo W, Sun R J, Song B W, et al. Laser shock peening of laser additive manufactured Ti6Al4V titanium alloy[J]. Surface and Coatings Technology, 2018, 349:503-510.

[21] Zhou B, Liu B, Zhang S G, et al. Microstructure evolution of recycled 7075 aluminum alloy and its mechanical and corrosion properties[J]. Journal of Alloys and Compounds, 2021, 879:160407. 
[22] Ma C H, Huang J H, Chen H. Residual stress measurement in textured thin film by grazing-incidence X-ray diffraction[J]. Thin Solid Films, 2002, 418(2):73-78.

[23] Liu Y G, Li H M, Li M Q. Characterization of surface layer in TC17 alloy treated by air blast shot peening[J]. Materials and Design, 2015, 65:120-126.

[24] Lu Y, Yang Y Q, Zhao J B, et al. Impact on Mechanical Properties and Microstructural Response of NickelBased Super-Alloy GH4169 Subjected to Warm Laser Shock Peening[J]. Materials, 2020, 13(22):5172.

[25] Liao Y L, Suslov S, Ye C, et al. The mechanisms of thermal engineered laser shock peening for enhanced fatigue performance[J]. Acta Materialia, 2012, 60(13-14):4997-5009.

[26] Cao Y P, Xu Y, Feng A X, et al. Experimental study of residual stress formation mechanism of 7050 Aluminum alloy sheet by laser shock processing[J]. Chinese journal of lasers, 2016,43(7): 133-140.

[27] Li Y H. Theory and technology of laser shock strengthening [M]. Science Press, 2013.

[28] Fabbro R, Fournier J, Ballard P, et al. Physics and applications of laser-shock processing[J]. Journal of laser application, 1998,10:265-279.

[29] Johnston W G, Gilman J J. Dislocation Velocities, Dislocation Densities, and Plastic Flow in Lithium Fluoride Crystals[J]. Journal of Applied Physics, 1959, 30(2):129-144.

[30] Lee W S, Lin C F, Chen T H, et al. Dynamic mechanical behaviour and dislocation substructure evolution of Inconel 718 over wide temperature range[J]. Materials Science and Engineering A, 2011, 528(19):6279-6286.

[31] Harold L, Michael R H. The effects of laser peering on high-cycle fatigue 7085-T7651 aluminum alloy. Materials Science and Engineering A, 2008, 477(1-2): 208-2 16 